\title{
CD147-mediated reprogrammed glycolytic metabolism potentially induces immune escape in the tumor microenvironment (Review)
}

\author{
XIAOFENG LI ${ }^{1-4}$ and WENGUI XU ${ }^{1-4}$ \\ ${ }^{1}$ Department of Molecular Imaging and Nuclear Medicine, Tianjin Medical University Cancer Institute and Hospital; \\ ${ }^{2}$ National Clinical Research Center for Cancer; ${ }^{3}$ Key Laboratory of Cancer Prevention and Therapy; \\ ${ }^{4}$ Tianjin's Clinical Research Center for Cancer, Tianjin 300060, P.R. China
}

Received October 12, 2018; Accepted February 27, 2019

DOI: 10.3892/or.2019.7041

\begin{abstract}
Impaired antitumor immunity or induced immunosuppression in the tumor microenvironment contributes significantly to tumor progression and resistance to immunotherapy. It is becoming increasingly recognized that dynamic metabolic programming orchestrates appropriate immune responses, whereas incorrect metabolic reprogramming

Correspondence to: Professor Wengui Xu, Department of Molecular Imaging and Nuclear Medicine, Tianjin Medical University Cancer Institute and Hospital, Huan-Hu-Xi Road, Ti-Yuan-Bei, He Xi, Tianjin 300060, P.R. China

E-mail:wxu06@tmu.edu.cn; wenguixy@yeah.net
\end{abstract}

Abbreviations: Akt/PKB, protein kinase B; AMPK, AMPactivated protein kinase; CD147, cluster of differentiation 147; CTLs, cytotoxic T lymphocytes; eIF-4E, eukaryotic translation initiation factor 4E; EMT, epithelial-to-mesenchymal transition; GLUT1/2/4, glucose transporter $1 / 2 / 4$; GSK-3 $\beta$, glycogen synthase kinase-3 $\beta$; HCC, hepatocellular carcinoma; HIF, hypoxia-inducible factor; HK2, hexokinase type 2; HRE, hypoxia-response element; LDHA, lactate dehydrogenase type A; MCT1/4, monocarboxylate transporter 1/4; MDM2, mouse double minute 2 homolog; MDSCs, myeloid-derived suppressor cells; mTOR, mammalian target of rapamycin; mTORC1, mTOR complex 1; P53, protein 53; P70S6K, ribosomal protein S6 kinase; PD-L1, programmed cell death ligand-1; PFK1/2, phosphofructokinase1/2; PFKM, phosphofructokinase; PKM2, pyruvate kinase muscle isoform 2; PI3K, phosphatidylinositol 3-kinase; PIP3, phosphatidylinositol 3,4,5-trisphosphate; PTEN, phosphatase and tensin homolog; Rheb, Ras homolog enriched in brain; Slug, zinc-finger transcriptional factor Slug; Snail, zinc-finger transcriptional factor Snail; SP1, specificity protein 1 ; TCF4, T-cell factor 4 ; TGF- $\beta$, transforming growth factor- $\beta$; TIGAR, TP53-induced glycolysis and apoptosis regulator; TILs, tumor-infiltrating lymphocytes; TSC1/TSC2, tuberous sclerosis complex $1 / 2$

Key words: aerobic glycolysis, tumor immune escape, metabolic manipulation may underlie aberrant immune remodeling. Furthermore, pathways that control cellular metabolism and immune cell function by transcriptional and post-transcriptional mechanisms are intimately interlinked, including hypoxia-inducible factor $1 \alpha$, c-Myc and phosphatidylinositol 3-kinase/protein kinase $\mathrm{B} / \mathrm{mammalian}$ target of rapamycin signaling. Immunometabolism is an emerging research field involving investigation of the interaction between immunological and metabolic processes. It is likely that high levels of nutrient competition and metabolic interplay exist between tumor cells and infiltrating immune cells in the local tumor milieu, which consequently leads to a reduction in antitumor immunity or immune cell dysfunction. Recently, a metabolic molecular mechanism responsible for the tumorigenic capacity of cluster of differentiation (CD)147, which exhibits high expression on the surface of various malignant tumor cells and is associated with tumor progression via multiple non-metabolic molecular mechanisms, was identified. The aim of the present review was to focus on the glycolytic mechanism mediated by the upregulation of CD147 in tumors and tumor-imposed metabolic restrictions on tumor-infiltrating immune cells, and the consequent immunological hyporesponsiveness. Cellular metabolism is becoming increasingly acknowledged as a key regulator of T-cell function, specification and fate, and the manipulation of metabolic programming may elucidate therapeutic options for immunological disorders and tumor immunotherapy.

\section{Contents}

1. Introduction

2. Glycolytic metabolism of tumor-infiltrating immune cells and underlying regulatory signaling pathways

3. Upregulated glycolytic metabolism in tumors and underlying molecular mechanisms

4. Glucose metabolic competition between tumor cells and tumor-infiltrating immune cells and consequent immune escape

5. Overexpression of CD147 in tumors and regulatory signaling pathways 
6. Therapeutic potential and clinical implications of metabolic intervention in tumors

7. Conclusions

\section{Introduction}

The two emerging hallmarks of metabolic reprogramming and evasion of immune destruction represent significant conceptual progress in the field of tumor research (1). Tumor cells preferentially uptake and utilize glucose via aerobic glycolysis, even in the presence of sufficient oxygen to support the mitochondrial oxidative respiration, a phenomenon referred to as the 'Warburg effect' (2). The role of the immune system in tumor cell recognition and elimination is becoming increasingly ambiguous, as tumor cells have developed several mechanisms to avoid immune responses (3-5). The functional impairment of effector $\mathrm{T}$ cells (Teffs) and the induction of immunosuppressive $T$ cells in the tumor micromilieu may lead to immune escape or evasion by cancer cells (6-8). The mechanisms responsible for T-cell dysfunction or hyporesponsiveness are complicated (9), and the association between tumor metabolic switch and immune tolerance has been attracting increasing attention (1,10-13).

The immune functions of Teffs are intimately associated with their metabolic regulation (14-18). Clonal expansion and antitumor function acquisition of $\mathrm{T}$ cells upon activation, which are energy-demanding processes, are accompanied by a marked shift in metabolism from energy-oriented catabolic oxidation in naive $\mathrm{T}$ cells to biosynthetic aerobic glycolysis in activated $\mathrm{T}$ cells (14). The metabolic and immunological functions of Teffs may be impaired by tumor cells due to the tumor-imposed nutrient depletion and accumulation of tumor-derived immunomodulatory metabolic intermediates, including lactate, in the tumor microenvironment (11-13). The manipulation of metabolic reprogramming in $\mathrm{T}$ cells is currently considered as a potential therapeutic target to regulate the antitumor function and fate of Teffs $(19,20)$.

Although several intracellular signaling pathway molecules in the metabolic reprogramming of tumor cells and Teffs have been identified, including hypoxia-inducible factor-1 (HIF-1), c-Myc and phosphatidylinositol 3-kinase (PI3K)/protein kinase B (Akt) $(15,21-26)$, how tumor cells cope with extracellular metabolic signals and transduce extracellular signals to intracellular stimuli remain to be fully elucidated. CD147, also referred to as HAb18G/CD147 in humans, is a transmembrane protein that has been reported to be overexpressed on the surface of various types of malignant tumor cells $(27,28)$. Upregulation of the expression of CD147 has been found to contribute significantly to malignant potential and poor prognosis through triggering the production and release of extracellular matrix metalloproteinase (MMP) and vascular endothelial growth factor (29-33). An increased dependence on aerobic glycolysis inevitably results in an increased production of lactic acid, and this surplus of lactic acid has to be exported in order to prevent cellular acidosis and maintain cellular homeostasis (34). Monocarboxylate transporters (MCTs) catalyze the transport of monocarboxylates, including L-lactate, across plasma membranes $(35,36)$. CD147 has also been described as a chaperone assisting in the folding, stability, membrane expression and functionality of MCTs (37), suggesting the involvement of CD147 in metabolic regulation (34). The aim of the present review was to highlight the immunosuppression in the tumor microenvironment induced by underlying glycolytic mechanism reprogramming and discuss the therapeutic potential of targeted metabolic manipulation in tumor immunotherapy.

\section{Glycolytic metabolism of tumor-infiltrating immune cells and underlying regulatory signaling pathways}

An emerging theme in immunology is that metabolic adaption and lymphocyte function are intimately linked, and changes in cellular metabolism have been shown to be associated with altered immunological function (18). Tumor cells have been the focus of investigations on the metabolic switch, although the metabolic reprogramming of immune cells, particularly tumor-infiltrating lymphocytes (TILs), has not been investigated as extensively. Warburg was also one of the first to examine leukocyte metabolism, and found that leukocyte stimulation led to a shift towards aerobic glycolysis from oxidative phosphorylation (OXPHOS), which is primarily used by resting leukocytes (38).

Distinct glycolytic metabolic programs are used by different immune cell subsets. Resting or naive $\mathrm{T}$ cells predominantly oxidize glucose-derived pyruvate, in addition to lipids and amino acids, via OXPHOS, to maintain quiescence and immune surveillance (39). Upon T cell activation, lipid oxidation is sharply reduced, and the cells rely instead on increased aerobic glycolysis to support extensive proliferation and Teff differentiation and function $(14,40)$. At the end of an immune response, a small population of antigen-specific $\mathrm{T}$ cells survives to become long-lived memory $\mathrm{T}$ cells, which revert back to a metabolic program comparable with that of resting T cells $(14,18,41)$. However, memory $\mathrm{T}$ cells exhibit an increased capacity for efficient energy generation, characterized by an increase in mitochondrial mass and, consequently, maximal mitochondrial spare respiratory capacity, which allows for the rapid and vigorous production of ATP upon repeat encounter with antigens $(42,43)$. In addition to Teffs, activated $\mathrm{T}$ cells can differentiate into regulatory $\mathrm{T}$ cells (Tregs), which serve a critical role in self-tolerance and immunosuppression $(3,44,45)$. Unlike Teffs, Tregs primarily use glucose-derived pyruvate and fatty acids to efficiently produce ATP through the tricarboxylic acid cycle and lipid $\beta$-oxidation (46). Distinct metabolic programs are required for functionally different T-cell lineage differentiation and commitment $(47,48)$. A comprehensive study by Michalek et al demonstrated that Teffs, including $\mathrm{T}$ helper (Th)1, Th2 and Th17 cells, were selectively increased in glucose transporter (GLUT)1 transgenic mice, and were dependent on a highly glycolytic metabolism (48). Tregs, by contrast, expressed a low level of GLUT1 and relied on high rates of lipid oxidation (48). Gene array analysis on $\mathrm{CD} 8^{+}$cytotoxic $\mathrm{T}$ cells under conditions of glucose deprivation or incubated in the presence or absence of 2-deoxy-D-glucose, which inhibits glycolysis, demonstrated that multiple key gene expression events and effector functions were selectively inhibited, including the production of interferon- $\gamma($ IFN- $\gamma)$, cell cycle progression and cytolytic 
activity (49). Consistently, impaired T-cell metabolism directly contributed to T-cell dysfunction and exhaustion in leukemia, whereas the genetically increased expression of GLUT1 and hexokinase 2 (HK2) may partially restore T-cell function (50). The upregulation of glycolysis by the transgenic overexpression of GLUT1 or glycolytic genes was sufficient to augment T-cell activation, ultimately resulting in lymphadenopathy and a systemic lupus erythematosus-like autoimmunity in aging mice (17).

c-Myc and HIF-1 $\alpha$ signaling pathways regulate the glycolytic metabolism of immune cells. The identification of transcription factors potentially responsible for the metabolic reprogramming upon T-cell activation revealed c-Myc and HIF-1 $\alpha$ as two of the top-ranked candidates, as both were found to be induced at the mRNA and protein levels upon T-cell stimulation (21). c-Myc specifically upregulates the expression of all glycolytic genes, including GLUT1, lactate dehydrogenase type A (LDHA), HK2 and pyruvate kinase muscle isoform 2 (PKM2). Subsequently, the acute genetic deletion of c-Myc markedly inhibits the upregulated glycolytic activity. In addition, an HIF-1 $\alpha$-mediated glycolytic switch regulates the balance of Th17/Treg differentiation (22,51). Th17-but not Treg-polarizing conditions elicited a HIF- $1 \alpha$-dependent acceleration of glycolysis via upregulation of glycolytic enzyme expression. By contrast, the inhibition of glycolytic metabolism resulted in the inhibition of Th17 differentiation and promotion of Treg development. Upon investigation of the underlying molecular mechanism, HIF-1 $\alpha$ was found to be selectively induced in Th17 differentiation through the mammalian target of rapamycin (mTOR) signaling pathway, whereas the deficiency of HIF-1 $\alpha$ led to decreased Th17 commitment but enhanced generation of Treg, which protected mice from experimental autoimmune encephalomyelitis (22).

Role of PI3K/Akt/mTOR signaling in the metabolism of T cells. $\mathrm{PI} 3 \mathrm{~K} / \mathrm{Akt}$ is activated by various stimuli in T lymphocytes, including $\mathrm{T}$ cell antigen receptor, costimulatory molecules, cytokine receptors and chemokine receptors $(23,24,52)$, and PI3K/Akt signaling serves a fundamental role in T-cell activity. For example, the trafficking of GLUTI to the cell surface and prevention of internalization in $\mathrm{T}$ cells are promoted by Akt (53). Of note, mTOR, as a downstream target of Akt, is activated by Akt and serves a key role in linking the activation of PI3K to Th-cell differentiation $(54,55)$. mTOR is a catalytic unit of two distinct multi-protein assemblies, referred to as mTOR complex (mTORC) 1 and mTORC2. The activation of mTORC1 can initiate a signaling cascade, which leads to metabolic reprogramming characterized by increased aerobic glycolysis. Of note, mTOR differentially regulates Teff and Treg lineage commitments through the activation of specific signal transducer and activator of transcription pathways and, consequently, the induction of lineage-specific transcription factors (54). By contrast, rapamycin treatment, which targets mTORC1, has been shown to exhibit an inhibitory effect on glycolytic switching upon T-cell activation (56). AMP-activated protein kinase (AMPK), as a well-known evolutionarily conserved energy sensor, is activated by an increased AMP/ATP ratio and acts in opposition to mTORC1 to maximize energy production via promoting mitochondrial phosphorylation (57). AMPK $\alpha 1^{-/-} \mathrm{T}$ cells exhibit an impaired ability to transit from an anabolic and glycolytic metabolism to a catabolic and lipid oxidative state under metabolic stress (58).

\section{Upregulated glycolytic metabolism in tumors and underlying molecular mechanisms}

It is well established that malignant transformation is associated with a disrupted balance between oncogenes and tumor suppressor genes. From a metabolic perspective, this is associated with a reprogrammed metabolism and constitutes a molecular basis for the accelerated aerobic glycolysis in tumors (59-62).

Role of $\mathrm{c}$-Myc in upregulated glycolytic metabolism in tumors. Accumulating evidence has confirmed that the MYC oncogene, the PI3Ks/Akt/ mTOR pathway and HIF-1 $(62,63)$, in addition to tumor suppressor p53, are implicated in the metabolic reprogramming of tumor cells (64-66) (Fig. 1). The MYC oncogene encodes a transcription factor, c-Myc, which links altered cellular metabolism to tumorigenesis (67). Generally, c-Myc directly and/or indirectly regulates the expression of genes involved in glucose, glutamine and nucleotide metabolism. For example, glycolytic genes, including LDHA are directly upregulated by c-Myc (68); however, c-Myc can repress the expression of microRNA-23a/b to indirectly promote the protein expression of glutaminase and metabolism of glutamine (69). The depletion of c-Myc has been shown to result in the repression of several genes encoding enzymes rate-limiting for deoxyribonucleoside triphosphates (dNTPs) metabolism, including thymidylate synthase, inosine monophosphate dehydrogenase 2 and phosphoribosyl pyrophosphate synthetase 2 . The depletion of c-Myc also leads to a decrease in dNTPs and inhibited cell proliferation (70). A number of glycolytic genes have been documented to be directly regulated by c-Myc in screens for c-Myc target genes, including GLUT1, HK2 and muscle phosphofructokinase $(71,72)$. In addition, c-Myc may cooperatively serve a pivotal role in hypoxic adaptation with HIF-1 through upregulating pyruvate dehydrogenase kinase 1 under non-normoxic conditions, thereby accelerating glycolytic metabolism by favoring the conversion of pyruvate to lactate and suppressing mitochondrial oxidative respiration (72-74).

Role of PI3K/Akt/mTOR signaling in glycolytic adaption in tumors. The PI3K/Akt/mTOR signaling pathway has been found to be activated at a high level and contribute to the metabolic transformation of tumors $(75,76)$ (Fig. 1). Akt, a serine/threonine kinase, has been shown to be constitutively activated in tumor cells through the amplification of PI3K, which phosphorylates membrane-associated phosphatidylinositol 4,5-bisphosphate (PIP2) to generate phosphatidylinositol 3,4,5-trisphosphate as an upstream activator of Akt (77). Human glioblastoma cells with constitutive Akt activity exhibit high rates of aerobic glycolysis through the direct effect of Akt on glucose metabolism, including upregulating the expression and/or localization of glucose transporters and glycolytic enzymes, including GLUT1 and HK2 (75). Akt also activates mTOR, which also contributes to the glucose metabolic reprogramming of tumor cells $(78,79)$. mTOR is 
also an upstream activator of HIF-1 and c-Myc in tumor cells, and high levels of Akt and mTOR activity lead to high HIF-1 activity and adaption to hypoxia $(78,79)$.

Adaption to hypoxia in glycolysis reprogramming in tumors. Hypoxia is a common feature of various malignant tumor cells (59), and the adaption of tumor cells to hypoxia is predominantly mediated by HIF-1, a key transcription factor that regulates nine of 10 enzymes involved in glycolytic energy metabolism (80). In addition, an accumulation of pyruvate and lactate derived from high rates of aerobic glycolysis may promote hypoxia-inducible gene expression independently of hypoxia via stimulating the induction and stability of HIF-1 $\alpha$ (81). Similarly, p53, which is mostly known for its tumor suppressor properties, is implicated in the metabolic adaption of tumors through decelerating glycolysis and accelerating mitochondrial oxidative respiration $(82,83)$. As a ubiquitin ligase, mouse double minute 2 homolog (Mdm2) may be phosphorylated by Akt and mediates the ubiquitylation and proteasome-dependent degradation of p53 (84).

Summary of molecular mechanisms mediated by glycolytic metabolism in tumors. In conclusion, relevant transporters and receptors on tumor cells integrate signals from growth factors, cytokines and nutrient availability in the tumor microenvironment to activate the PI3K/Akt/mTOR signaling pathway, which regulates the expression of various transcription factors, including c-Myc, HIF-1 and p53, leading to the reprogramming of glucose metabolism in tumors. Of note, a reciprocal interaction exists between molecular signaling pathways regulating c-Myc, HIF-1 and p53, forming a complicated and intricate regulatory network controlling the metabolic switch in tumors (85).

\section{Glucose metabolic competition between tumor cells and tumor-infiltrating immune cells and consequent immune escape}

A number of mechanisms for the immune evasion of tumor cells have been elaborated (86), including the downregulation of tumor-associated antigen and costimulatory molecule expression, and the upregulation of inhibitory immunomodulatory molecules and immunosuppressive cells $(3,9,87)$. The metabolic interplay between tumor cells and infiltrating lymphocytes has been suggested to be an important metabolic mechanism underlying immunological escape of tumor cells (88) (Fig. 2). The similarity of tumor cell and activated lymphocyte metabolism is not coincidental, as is it essential that their metabolism matches the functional demands of the cells. Rapid growth and proliferation are necessary for tumor cells and activated lymphocytes; therefore, they preferentially select the more biosynthesis-efficient aerobic glycolysis and anabolism over the energy-oriented mitochondrial OXPHOS.

Role of tumor-imposed glucose restriction in antitumor immune escape. It is likely that intense nutrient competition exists between tumor cells and TILs in the tumor microenvironment, as tumor cells may deplete nutrients due to their dependence on enhanced aerobic glycolysis (10). This tumor-imposed glucose restriction may lead to TIL dysfunction due to reduced glucose uptake and metabolic reprogramming. In an established mouse model of progressing and regressing tumors, the progressing tumors exhibited higher rates of glycolytic activity compared with regressing tumors, suggesting that progressing tumors consume more glucose. Consistently, $\mathrm{T}$ cells in progressing tumors exhibited decreased phosphorylation of eukaryotic translation initiation factor 4E-binding protein 1 (4EBP1) and S6 kinase compared with that in regressing tumors. However, Tregs and M2 macrophages, neither of which depend on enhanced aerobic glycolysis, but rather on fatty acid oxidation, are unaffected by the glucose-depleted tumor microenvironment, and may suppress the antitumor immune response.

Role of metabolites produced by enhanced tumor glycolysis in tumor-infiltrating immune cell dysfunction. In addition to tumor-imposed nutrient limitation for tumor-infiltrating immune cells, metabolites, including the enhanced lactate production by tumors due to increased dependence on glycolysis $(59,62,89)$, are suggested to be key metabolic components in the communication between tumor cells and tumor-infiltrating immune cells $(34,90)$. It is important that the excess cellular lactate produced by tumors is exported, mainly by MCTs (MCT1/MCT4), in order to prevent acidosis in tumor cells, which leads to the accumulation of lactate in the tumor milieu (91). Lactate has been shown to promote cancer cell stemness (92) and metastasis (93) through the increased production of several tumor progression-promoting factors, including transforming growth factor (TGF)- $\beta(94,95)$, hyaluronic acid and CD44 (96). In addition to its direct effect on tumor cells, lactate act as an immunomodulator, mediating the immune evasion of tumor cells (97). The exogenous lactate treatment of natural killer (NK) cells inhibited their cytotoxicity directly and indirectly by increasing the number of myeloid-derived suppressor cells (MDSCs), which may repress NK cell function $(12,98)$. By contrast, LDHA-deleted pancreatic cancer cell xenografts, with a defect in lactate production, exhibited improved cytolytic function of NK cells in C57BL/6 mice, with higher expression of perforin and granzyme and a decreased number of MDSCs in the spleen $(12,98)$. Furthermore, the immunomodulatory effects of lactic acid have been demonstrated not only for dendritic cells, but also for T cells (13). However, the export of excess lactic acid by activated T cells is inhibited due to the lactic acid gradient between the cytoplasm and extracellular milieu, due to the accumulation of lactic acid secreted by surrounding tumor cells with high rates of glycolysis. To conclude, the accumulation of tumor-derived lactate in the extracellular milieu may lead to a metabolic obstruction in cytotoxic T lymphocytes (CTLs); subsequently, CTLs become hyporesponsive, exhibiting decreased proliferation, cytokine secretion and cytotoxic activity $(13,99,100)$. Tregs and M2 macrophages are not affected by the presence of high levels of lactate, as their distinct metabolic program relies mainly on fatty acid oxidation rather than aerobic glycolysis (48).

An acidic tumor microenvironment resulting from upregulated tumor glycolytic metabolism leads to decreased antitumor immunity. As MCT1 and MCT4 are $\mathrm{H}^{+} /$lactate symporters, lactate efflux via MCT1/MCT4 is accompanied by $\mathrm{H}^{+}$transport, which eventually creates an acidic microenvironment (97). 


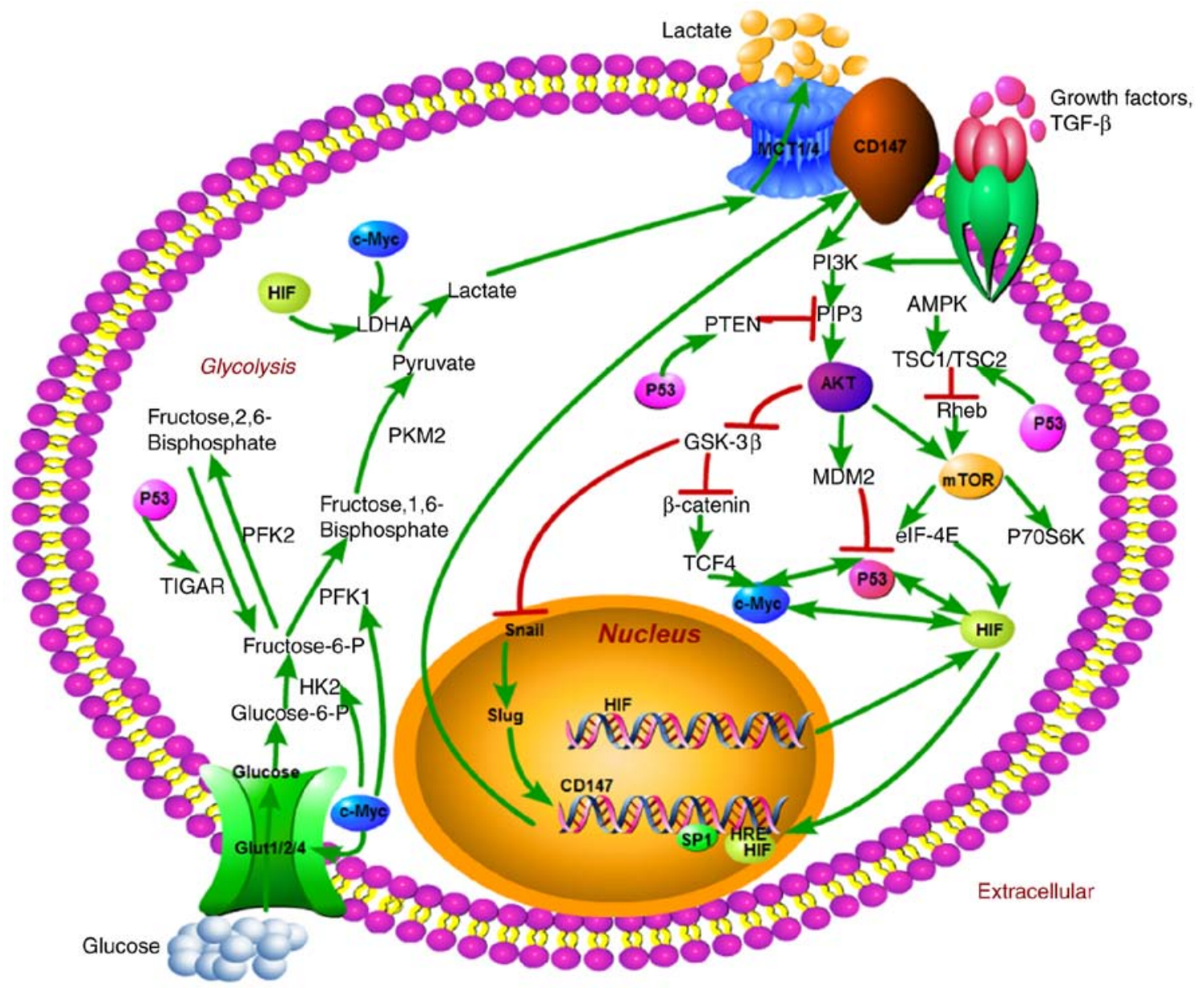

Figure 1. Schematic representation of the regulation of altered glucose metabolism associated with the upregulation of CD147 and the underlying molecular mechanism in tumors. Green arrows represent stimulation/activation and red ends represent inhibition. CD147, cluster of differentiation 147.

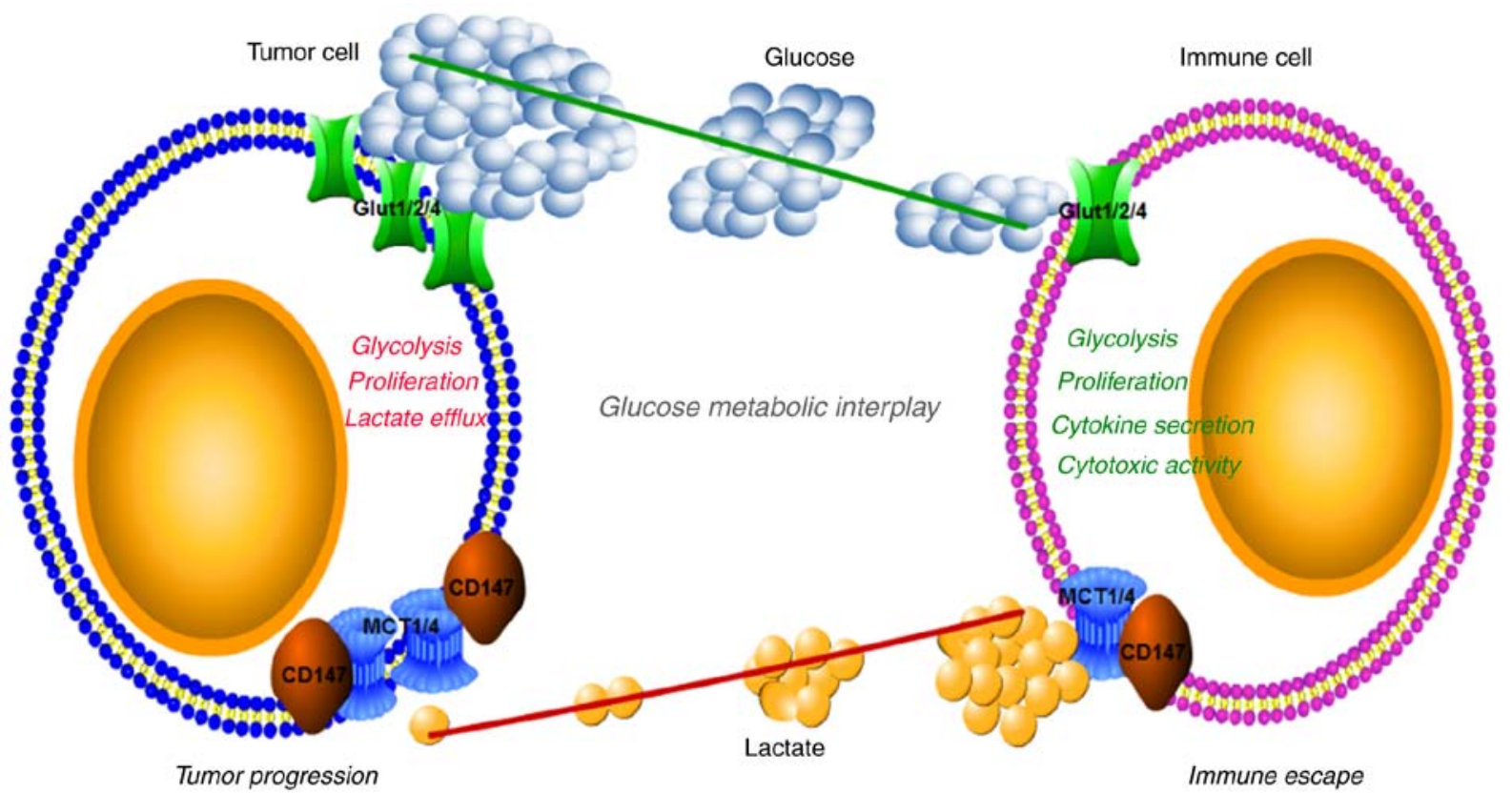

Figure 2. Schematic representation of immune evasion mediated by glucose metabolic interplay between tumor cells and immune cells associated with overexpression of CD147 on tumor cells. Tumor-imposed glucose restriction mediated by enhanced aerobic glycolysis in tumor induced by the overexpression of CD147 may lead to reduced glucose uptake by tumor-infiltrating immune cells and subsequent immune cell dysfunction. In addition, the increased lactate production by tumor cells due to enhanced aerobic glycolysis may be a key metabolic factor in the communication between tumor cells and infiltrating immune cells through inhibiting glycolysis, proliferation, cytokine secretion and cytotoxic activity of immune cells. The balance of glucose metabolic interplay is shifted towards tumor cells, and the upregulated expression of CD147 in tumor cells significantly contributes to tumor progression and immune evasion. Red, upregulation; green, downregulation. CD147, cluster of differentiation 147; MCT1/4, monocarboxylate transporter 1/4; GLUT1/2/4, glucose transporter 1/2/4. 
Extracellular acidosis is characteristic of the tumor micromilieu, and the local acidification allows tumor cells to be aggressive via increased extracellular matrix degradation and enhanced survival and metastasis $(101,102)$. In addition to the promoting effect of extracellular acidosis on tumor progression, the acidic microenvironment is important in the immune evasion of tumor cells mediated by immune cell dysfunction. Interferon (IFN)- $\gamma$, as a critical mediator of the differentiation of Th1 and Th2 cells, promotes Th1 polarization and inhibits Th2 differentiation (103). However, IFN- $\gamma$ is acid-labile and likely to be denatured in an acidic milieu, which diverts Th-cell differentiation from the antitumor Th1 lymphocytes towards the tumor-promoting Th2 lymphocytes (104). HIF-1, a key transcription factor predominantly mediating the adaptation of tumor cells to hypoxia, may not be degraded under sufficient oxygen supply (105), thereby contributing to HIF-dependent glycolytic reprogramming in tumor cells and, consequently, decreased antitumor immunity.

HIF-1-associated signaling pathway in immune cells directly contributes to tumor immunosuppression. Given the profound effect of HIF-1 on gene regulation, T-cell differentiation is likely controlled by HIF-1 $(15,22)$. Furthermore, TGF- $\beta 1$ may stabilize HIF-1 through the inhibition of prolyl hydroxylase 2 under hypoxic conditions (106). A screening of key transcription factors for T-cell differentiation during inflammatory hypoxia of the mucosa revealed forkhead box (FOX)P3 as a direct target of HIF-1, and it has also been demonstrated that the hypoxic induction of FOXP3 and accumulation of Treg require both HIF-1 and TGF- $\beta 1$ (107). HIF-1 has also been identified as a decisive factor in T-cell differentiation to Th17 or Tregs by promoting Th17-polarization and inhibiting Treg differentiation $(22,51)$. TGF- $\beta 1$ may be induced in hypoxia (108), and is also key role the differentiation of Th17 and Tregs (109). It is reasonable to hypothesize that the Th17/Treg balance is an integral outcome of HIF-1, TGF- $\beta 1$ and inflammatory cytokine interplay in the local tumor milieu $(22,51,107)$. The exposure of human breast and prostate cells, and mouse melanoma and mammary carcinoma cells to hypoxia resulted in the upregulation of programmed cell death ligand-1 (PD-L1), an important immunoinhibitory molecule, on the surface of tumor cells in an HIF-1-dependent manner, which eventually contributed to tumor cell evasion from antitumor immunity via the increased apoptosis of CTLs due to the enhanced PD-1/PD-L1 interaction (110). Although the mechanisms underlying increased the expression of PD-L1 on tumor cells remain to be fully elucidated, the hypoxia-induced upregulation of PD-L1 on tumor cells may represent a novel mechanism responsible for hypoxia-mediated immune evasion of tumor cells. In addition to the previously known inhibitory effects of TGF- $\beta 1$ on T-cell differentiation and function, TGF- $\beta 1$ has also been found to mediate T-cell hyporesponsiveness, in part through the enhanced expression of PD-1 on tumor-infiltrating antigen-specific $\mathrm{T}$ cells induced by mothers against decapentaplegic homolog 3 (Smad3)-dependent signaling $(111,112)$.

\section{Overexpression of CD147 in tumors and regulatory signaling pathways}

CD147 may significantly contribute to tumor growth, invasion, metastasis and angiogenesis $(29,30,113)$, particularly in human hepatocellular carcinoma (HCC), mainly via triggering the production of MMP and interacting with various ligands involved in neoplastic cell behavior, including integrin $\alpha 3 \beta 1$ (114) and $\alpha 6 \beta 1$ (115), and Annexin II (116). The non-metabolic molecular mechanisms responsible for the tumor progression associated with the upregulation of CD147 were discussed in a previous review (38).

Metabolic mechanisms responsible for tumor progression associated with the upregulation of CD147. In addition to non-metabolic molecular mechanisms responsible for the tumor progression associated with the upregulation of CD147, a metabolic molecular basis has become a focus of investigations. Blocking CD147 with a targeted monoclonal antibody or silencing CD147 by small interfering RNA has been shown to result in a marked decrease in glycolytic energy metabolism $(117,118)$. Consistently, a study by Huang et al demonstrated that CD147 acts as an important regulator of cell proliferation through promoting glucose metabolic reprogramming by the post-transcriptional inhibition of $\mathrm{p} 53$ via the activation of $\mathrm{PI} 3 \mathrm{~K} / \mathrm{Akt} / \mathrm{Mdm} 2$ signaling promoted by MCT1-induced lactate export in HCC (119) (Fig. 1). CD147 is increasingly recognized as being implicated in glucose metabolism reprogramming in tumors through gain/loss-of-function studies $(92,120)$.

Regulatory signaling pathway for the expression of CD147. According to the regulation of CD147, it is well established that the tumor micromilieu serves an important role in the overexpression of CD147 on the surface of tumor cells. As is known, TGF- $\beta 1$ induces epithelial-to-mesenchymal transition (EMT) via Smad-dependent and -independent signaling pathways (121-123). A study by Wu et al demonstrated a positive correlation between the expression of CD147 and typical EMT markers, revealed that CD147 is a Slug target gene, and demonstrated that the upregulation of CD147 involves activation of the PI3K/Akt-GSK3 $\beta$-Snail-Slug signaling pathway through the stimulation of TGF- $\beta 1$ (124). A series of transcription factors have been found to be implicated in the fundamental metabolic adaptation of tumors to hypoxia, among which HIF-1 is critical to this process $(125,126)$. HIF-1 is a heterodimer that consists of a constitutively expressed HIF-1 $\beta$ subunit and an oxygen-sensitive HIF-1 $\alpha$ subunit (127). Under hypoxic conditions, HIF- $1 \alpha$ binds to a conserved DNA consensus, referred to as hypoxia-responsive element (HRE), on the promoters of numerous hypoxia-responsive genes. There are two HIF-1-binding sites and three specificity protein 1 (SP1)-binding sites in the 3 ' and 5' flanking regions of the CD147 gene, respectively $(128,129)$. Consistently, a genome-wide chromatin immunoprecipitation-on-chip assay and immunohistochemical staining identified CD147 as a novel hypoxia-responsive molecule. The identification of key molecules engaged in epithelial solid tumor glycolytic switch confirmed that the upregulation of CD147 was mainly mediated through the combined effect of HIF-1 $\alpha$ and SP1 on activation of the CD147 promoter (120). A study by Kong et al also reported that upregulation of the expression of CD147 was mediated by promoter hypomethylation through increased SP1 binding in human HCC and lung cancer $(127,130)$. 
In conclusion, the signaling pathways responsible for the overexpression of CD147 on tumor cells mainly include TGF- $\beta 1$ and HIF- $1 \alpha$, which are pivotal in tumor glycolysis and immunosuppression.

\section{Therapeutic potential and clinical implications of metabolic intervention in tumors}

Successful chemotherapeutic tumor treatment generally depends on the rapid proliferation of tumor cells. However, undesirable side-effects on normal proliferating cells are inevitable due to the non-specific nature of this treatment. Therefore, therapeutic strategies based on specifically targeting the 'metabolic transformation' of tumor cells may be a preferred approach (63). Various potential agents targeted against the altered metabolism of tumor cells are currently in clinical trials, and several more are under development.

Therapeutic drugs for manipulating the metabolic activity of immune cells to prevent immune cell hyporesponsiveness in tumors. Apart from tumor cells themselves, manipulating the metabolic activity of immune cells to prevent immune cell hyporesponsiveness in tumors is currently considered a promising approach in cancer therapy $(11,19,20)$. The fundamental principle of modulating the metabolism of $\mathrm{T}$ cells is to favor anabolic glycolysis rather than catabolic oxidative respiration. Specific antibodies against nutrient transporters have been confirmed as potential pharmacological agents targeting T-cell metabolism. For example, blockade of GLUT1 on T cells has been found to decrease glucose uptake, thus leading to T-cell dysfunction (17). The blocking of co-inhibitory receptors has been suggested as a promising immunotherapy option for enhancing antitumor immunity to eliminate tumor cells (131-134). Cytotoxic T-lymphocyte-associated protein 4 (CTLA-4) and PD-1, two well-known inhibitory receptors on $\mathrm{T}$ cells, are induced upon $\mathrm{T}$-cell activation to control and moderate excessive immune responses, acting as checkpoints (131). However, CTLA-4 and PD-1 signaling have been shown to restrict T-cell activation and function by downregulating aerobic glycolysis $(10,135)$. Therefore, it is hypothesized that checkpoint blocking may relieve the suppression of antitumor immunity, in part through remodeling T-cell metabolic programming to enhance nutrient uptake and glycolytic metabolism, consequently restoring their capacity to kill tumor cells (11). PD-L1 also has a PD-L1 and PD-1 interaction-independent metabolic function $(111,136)$. PD-L1 on tumor cells is important for Akt/mTOR signaling, which in turn increases the rate of glycolysis through promoting the translation of glycolytic enzymes. Blocking PD-L1 may directly decrease glycolysis in tumors, increasing the nutrient availability in the extracellular tumor milieu for infiltrating lymphocytes $(10,11)$.

Direct and indirect therapeutic drugs targeting metabolic adaptation of tumor cells. In general, therapeutic drugs targeting the metabolic adaptation of tumor cells may be divided in two categories, namely direct and indirect. Indirect drugs target aberrant signaling pathways relevant to metabolic transformation in tumor cells, including the HIF-1 $\alpha$ (137), c-Myc (67,138), PI3K/Akt/mTOR (139-141) and AMPK (142) pathways. For example, metformin, a drug originally designed to treat patients with type 2 diabetes (143), may activate the AMPK signaling pathway to oppose mTORC1, subsequently decreasing glycolytic metabolism and increasing OXPHOS in tumor cells to control tumor progression $(144,145)$.Consistently, patients with type 2 diabetes who were treated with metformin were more likely to remain cancer-free over 8 years compared with those who received other treatments $(146,147)$. Metformin is currently in phase I and II clinical trials for cancer therapy. Direct drugs comprise antagonists against multiple metabolic enzymes and several metabolites in glucose, amino acid, lipid and nucleotide metabolism (63). This review focuses on glycolytic metabolism. Almost all enzymes involved in every stage of glycolysis may represent potential targets, particularly tumor-specific enzyme isoforms and glycolytic metabolites, including PKM2 $(129,148)$ and lactic acid $(90,102)$. In terms of CD147, it has been reported in patients with HCC that targeted radioimmunotherapy with ${ }^{131}$ I-labeled HAb18 $\mathrm{F}\left(\mathrm{ab}^{\prime}\right) 2$ metuximab monoclonal antibody injection (licartin), which is a radiolabelled anti-CD147 monoclonal antibody, effectively prevented the recurrence and metastasis of HCC following hepatectomy and liver transplantation (149). Based on the evidence described above, it is reasonable, to a certain extent at least, to attribute the antineoplastic capacity of licartin to its ability to inhibit the glycolytic metabolism of HCC cells. Combination therapy of ${ }^{131}$ I-labeled metuximab and other metabolic transformation-targeting drugs may be more beneficial for antitumor treatment compared with monotherapy.

Targeted delivery of therapeutic drugs and combination treatment with metabolic intervention and antitumor immunotherapy. Regardless of the modulation of cellular metabolism in tumor cells or T cells, targeted delivery of specific drugs in the body is crucial for preventing off-target effects. Transporter-facilitated drug uptake $(150,151)$, bi-specific antibodies $(152,153)$ and nanoparticle-mediated delivery $(154,155)$ have been developed to optimize drug efficacy. Optimal Teff function in the tumor microenvironment is necessary for successful adoptive T-cell immunotherapy. Combination treatment comprising metabolic intervention and adoptive T-cell immunotherapy appears promising for metabolic reprogramming of $\mathrm{T}$ cells to exert effective antitumor immunity (19,20). As reported previously, CD147 serves an important role in the reprogramming of glucose metabolism and cell proliferation in HCC cells (119), and a targeted radiolabeled anti-CD147 monoclonal antibody (licartin) effectively prevented the recurrence and metastasis of HCC following hepatectomy and liver transplantation (149). The blocking of CD147 inhibited the enhanced glycolysis of HCC cells and contribute to improved antitumor immunity in the tumor microenvironment, which is exactly what current endeavors are aiming to prove. Combination therapy comprising CD147 intervention and tumor immunotherapy is likely to lead to more marked antitumor effects than monotherapy. However, the timing of adoptive Teffs entering the local tumor milieu is an important issue requiring consideration. Using inhibitors of glycolysis prior to the adoptive transfer of T cells may assist in remodeling metabolic function in T cells in a hospitable tumor milieu with nutrient repletion $(19,20)$. 


\section{Conclusions}

CD147 exhibits high expression on the surface of a variety of malignant tumor cells, and serves an important role in neoplastic cell behavior via non-metabolic and metabolic molecular mechanisms. Specifically, the involvement of CD147 in tumor glucose metabolism reprogramming has been suggested, as CD147 can assist in the folding, stability, membrane expression and functionality of MCTs as a chaperone in the transport of monocarboxylates, including L-lactate, across the plasma membrane in tumor glycolysis. The metabolic interplay between tumor cells and infiltrating lymphocytes has been increasingly recognized as an important metabolic mechanism underlying the immune escape of tumor cells, including intense competition for nutrients between tumor cells and TILs in the tumor microenvironment, and an accumulation of tumor-derived lactate in the extracellular milieu. HIF-1 $\alpha$, c-Myc, PI3K/Akt/mTOR and AMPK signaling are considered to be important metabolic pathways responsible for metabolic reprogramming and antitumor immunoediting in tumors. Therefore, the manipulation of cellular metabolism may be of value for the treatment of immunological disorders and tumor immunotherapy.

\section{Acknowledgements}

The authors would like to thank Professor Juan Li of Tianjin Medical University for their assistance in improving schematic diagrams and in manuscript submission.

\section{Funding}

The present study was supported by the National Natural Science Foundation of China (grant nos. 81601377 and 81501984), the National Science and Technology Major Project (grant no. 2013ZX09303001), the Tianjin Natural Science Fund (grant nos. 16JCZDJC35200 and 17JCYBJC25100), the Incubation Project of National Clinical Research Center for Cancer (grant no. N14B09) and the Tianjin Medical University Cancer Institute and Hospital Fund (grant no. Y1601).

\section{Availability of data and materials}

Not applicable.

\section{Authors' contributions}

$\mathrm{XL}$ and WX conceived, designed the study and wrote the manuscript. All authors read and approved the manuscript and agree to be accountable for all aspects of the research in ensuring that the accuracy or integrity of any part of the work are appropriately investigated and resolved.

\section{Ethics approval and consent to participate}

Not applicable.

\section{Patient consent for publication}

Not applicable.

\section{Competing interests}

The authors declare that they have no competing interests.

\section{References}

1. Kareva I and Hahnfeldt P: The emerging 'hallmarks' of metabolic reprogramming and immune evasion: Distinct or linked? Cancer Res 73: 2737-2742, 2013.

2. Warburg O: On respiratory impairment in cancer cells Science 124: 269-270, 1956.

3. Li X, Peng J, Pang Y, Yu S, Yu X, Cheng PC, Wang WZ, Han WL, Zhang J, Yin YH and Zhang Y: Identification of a FOXP $3{ }^{+} \mathrm{CD}^{+} \mathrm{CD}^{2} 6^{+}$population with immunosuppressive function in cancer tissues of human hepatocellular carcinoma. Sci Rep 5: 14757, 2015.

4. Kalathil SG and Thanavala Y: High immunosuppressive burden in cancer patients: A major hurdle for cancer immunotherapy. Cancer Immunol Immunother 650: 813-819, 2016.

5. Wargo JA, Reddy SM, Reuben A and Sharma P: Monitoring immune responses in the tumor microenvironment. Curr Opin Immunol 41: 23-31, 2016.

6. Josefowicz SZ, Lu LF and Rudensky AY: Regulatory T cells: Mechanisms of differentiation and function. Annu Rev Immunol 30: 531-564, 2012.

7. Hansen $\mathrm{M}$ and Andersen $\mathrm{MH}$ : The role of dendritic cells in cancer. Semin Immunopathol 9: 307-316, 2017.

8. Ni L and Dong C: New checkpoints in cancer immunotherapy. Immunol Rev 276: 52-65, 2017.

9. Speiser DE, Ho PC and Verdeil G: Regulatory circuits of T cell function in cancer. Nat Rev Immunol 16: 599-611, 2016.

10. Chang CH, Qiu J, O'Sullivan D, Buck MD, Noguchi T, Curtis JD, Chen Q, Gindin M, Gubin MM, van der Windt GJ, et al: Metabolic competition in the tumor microenvironment is a driver of cancer progression. Cell 162: 1229-1241, 2015.

11. Siska PJ and Rathmell JC: T cell metabolic fitness in antitumor immunity. Trends Immunol 36: 257-264, 2015.

12. Gottfried E, Kunz-Schughart LA, Ebner S, Mueller-Klieser W, Hoves S, Andreesen R, Mackensen A and Kreutz M: Tumor-derived lactic acid modulates dendritic cell activation and antigen expression. Blood 107: 2013-2021, 2006.

13. Fischer K, Hoffmann P, Voelk1 S, Meidenbauer N, Ammer J, Edinger M, Gottfried E, Schwarz S, Rothe G, Hoves S, et al: Inhibitory effect of tumor cell-derived lactic acid on human T cells. Blood 109: 3812-3819, 2007.

14. MacIver NJ, Michalek RD and Rathmell JC: Metabolic regulation of T lymphocytes. Annu Rev Immunol 31: 259-283, 2013.

15. Gerriets VA and Rathmell JC: Metabolic pathways in T cell fate and function. Trends Immunol 33: 168-173, 2012.

16. Chang CH, Curtis JD, Maggi LB Jr, Faubert B, Villarino AV, O'Sullivan D, Huang SC, van der Windt GJ, Blagih J, Qiu J, et al: Posttranscriptional control of $\mathrm{T}$ cell effector function by aerobic glycolysis. Cell 153: 1239-1251, 2013.

17. Macintyre AN, Gerriets VA, Nichols AG, Michalek RD, Rudolph MC, Deoliveira D, Anderson SM, Abel ED, Chen BJ, Hale LP, et al: The glucose transporter Glut1 is selectively essential for CD4 $\mathrm{T}$ cell activation and effector function. Cell Metab 20: 61-72, 2014

18. Pearce EL, Poffenberger MC, Chang CH and Jones RG: Fueling immunity: Insights into metabolism and lymphocyte function. Science 42: 1242454, 2013.

19. Chang $\mathrm{CH}$ and Pearce EL: Emerging concepts in immunotherapy-T cell metabolism as a therapeutic target. Nat Immunol 17: 364-368, 2016.

20. O'Sullivan D and Pearce EL: Targeting T cell metabolism for therapy. Trends Immunol 36: 71-80, 2015.

21. Wang R, Dillon CP, Shi LZ, Milasta S, Carter R, Finkelstein D, McCormick LL, Fitzgerald P, Chi H, Munger J, et al: The transcription factor Myc controls metabolic reprogramming upon T lymphocyte activation. Immunity 35: 871-882, 2011.

22. Shi LZ, Wang R, Huang G, Vogel P, Neale G, Green DR and Chi H: HIF1alpha-dependent glycolytic pathway orchestrates a metabolic checkpoint for the differentiation of TH17 and Treg cells. J Exp Med 208: 1367-1376, 2011.

23. So L and Fruman DA: PI3K signalling in B- and T-lymphocytes: New developments and therapeutic advances. Biochem J 442: 465-841, 2012. 
24. Han JM, Patterson SJ and Levings MK: The role of the PI3K signaling pathway in $\mathrm{CD} 4^{+} \mathrm{T}$ cell differentiation and function. Front Immunol 3: 245, 2012.

25. Powell JD, Pollizzi KN, Heikamp EB and Horton MR: Regulation of immune responses by mTOR. Annu Rev Immunol 30: 39-68, 2012.

26. Chi HB: Regulation and function of mTOR signaling in $\mathrm{T}$ cell fate decisions. Nat Rev Immunol 12: 325-338, 2012.

27. Weidle UH, Scheuer W, Eggle D, Klostermann S and Stockinger H: Cancer-related issues of CD147. Cancer Genomics Proteomics 7: $157-169,2010$.

28. Riethdorf S, Reimers N, Assmann V, Kornfeld JW, Terracciano L, Sauter $\mathrm{G}$ and Pantel K: High incidence of EMMPRIN expression in human tumors. Int J Cancer 119: 1800-1810, 2006.

29. Xu J, Xu HY, Zhang Q, Song F, Jiang JL, Yang XM, Mi L, Wen N, Tian R, Wang L, et al: HAb18G/CD147 functions in invasion and metastasis of hepatocellular carcinoma. Mol Cancer Res 5: 605-614, 2007.

30. Zhang Q, Zhou J, Ku XM, Chen XG, Zhang L, Xu J, Chen GS Li Q, Qian F, Tian R, et al: Expression of CD147 as a significantly unfavorable prognostic factor in hepatocellular carcinoma. Eur J Cancer Prev 16: 196-202, 2007.

31. Zheng HC, Takahashi H, Murai Y, Cui ZG, Nomoto K, Miwa S, Tsuneyama K and Takano Y: Upregulated EMMPRIN/CD147 might contribute to growth and angiogenesis of gastric carcinoma: A good marker for local invasion and prognosis. Br J Cancer 95: 1371-1378, 2006.

32. Tang Y, Nakada MT, Kesavan P, McCabe F, Millar H, Rafferty P, Bugelski P and Yan L: Extracellular matrix metalloproteinase inducer stimulates tumor angiogenesis by elevating vascular endothelial cell growth factor and matrix metalloproteinases. Cancer Res 65: 3193-3199, 2005.

33. Tang Y, Nakada MT, Rafferty P, Laraio J, McCabe FL, Millar H, Cunningham M, Snyder LA, Bugelski P and Yan L: Regulation of vascular endothelial growth factor expression by EMMPRIN via the PI3K-Akt signaling pathway. Mol Cancer Res 4: 371-377, 2006.

34. Kennedy KM and Dewhirst MW: Tumor metabolism of lactate: The influence and therapeutic potential for MCT and CD147 regulation. Future Oncol 6: 127-148, 2010.

35. Halestrap AP and Price NT: The proton-linked monocarboxylate transporter (MCT) family: Structure, function and regulation. Biochem J 343: 281-299, 1999.

36. Halestrap AP and Wilson MC: The monocarboxylate transporter family-role and regulation. IUBMB Life 64: 109-119, 2012

37. Kirk P, Wilson MC, Heddle C, Brown MH, Barclay AN and Halestrap AP: CD147 is tightly associated with lactate transporters MCT1 and MCT4 and facilitates their cell surface expression. EMBO J 19: 3896-3904, 2000.

38. Li XF, Yu XZ, Song XY, Dai D and Xu WG: The altered glucose metabolism in tumor and a tumor acidic microenvironment associated with extracellular matrix metalloproteinase inducer and monocarboxylate transporters. Oncotarget 7: 23141-23155, 2016.

39. Kroemer G and Pouyssegur J: Tumor Cell Metabolism: Cancer's Achilles' Heel. Cancer Cell 13: 472-482, 2008.

40. Hsu PP and Sabatini DM: Cancer cell metabolism: Warburg and beyond. Cell 134: 703-707, 2014

41. Levine AJ and Puzio-Kuter AM: The control of the metabolic switch in cancers by oncogenes and tumor suppressors genes. Science 330: 1340-1344, 2010.

42. Tennant DA, Duran RV and Gottlieb E: Targeting metabolic transformation for cancer therapy. Nat Rev Cancer 10: 267-277, 2010.

43. Madan E, Gogna R, Bhatt M, Pati U, Kuppusamy P and Mahdi AA: Regulation of glucose metabolism by p53: Emerging new roles for the tumor suppressor. Oncotarget 2: 948-957, 2011.

44. Zhang C, Liu J, Wu R, Liang Y, Lin M, Liu J, Chan CS, Hu W and Feng Z: Tumor suppressor p53 negatively regulates glycolysis stimulated by hypoxia through its target RRAD. Oncotarget 5 : 5535-5546, 2014

45. Schwartzenberg-Bar-Yoseph F, Armoni M and Karnieli E: The tumor suppressor p53 down-regulates glucose transporters GLUT1 and GLUT4 gene expression. Cancer Res 64: 2627-2633, 2004.

46. Dang CV, Le A and Gao P: MYC-induced cancer cell energy metabolism and therapeutic opportunities. Clin Cancer Res 15: 6479-6483, 2009.

47. Shim H, Dolde C, Lewis BC, Wu CS, Dang G, Jungmann RA, Dalla-Favera R and Dang CV: c-Myc transactivation of LDH-A Implications for tumor metabolism and growth. Proc Natl Acad Sci USA 94: 6658-6663, 1997.
48. Michalek RD, Gerriets VA, Jacobs SR, Macintyre AN, MacIver NJ, Mason EF, Sullivan SA, Nichols AG and Rathmell JC: Cutting Edge: Distinct glycolytic and lipid oxidative metabolic programs are essential for effector and regulatory $\mathrm{CD}^{+} \mathrm{T}$ cell subsets. J Immunol 186: 3299-3303, 2011.

49. Osthus RC, Shim H, Kim S, Li Q, Reddy R, Mukherjee M, Xu Y, Wonsey D, Lee LA and Dang CV: Deregulation of glucose transporter 1 and glycolytic gene expression by c-Myc. J Biol Chem 275: 21797-21800, 2000.

50. Kim JW, Gao P, Liu YC, Semenza GL and Dang CV: Hypoxia-inducible factor 1 and dysregulated c-Myc cooperatively induce vascular endothelial growth factor and metabolic switches hexokinase 2 and pyruvate dehydrogenase kinase 1. Mol Cell Biol 27: 7381-7393, 2007.

51. Dang CV, Kim JW, Gao P and Yustein J: The interplay between MYC and HIF in cancer. Nat Rev Cancer 8: 51-56, 2008.

52. Kim JW, Tchernyshyov I, Semenza GL and Dang CV: HIF-1 mediated expression of pyruvate dehydrogenase kinase: A metabolic switch required for cellular adaptation to hypoxia. Cell Metab 3: 177-185, 2006.

53. Elstrom RL, Bauer DE, Buzzai M, Karnauskas R, Harris MH, Plas DR, Zhuang H, Cinalli RM, Alavi A, Rudin CM and Thompson CB: Akt stimulates aerobic glycolysis in cancer cells. Cancer Res 64: 3892-3899, 2004.

54. Makinoshima H, Takita M, Saruwatari K, Umemura S, Obata Y, Ishii G, Matsumoto S, Sugiyama E, Ochiai A, Abe R, et al: Signaling through the phosphatidylinositol 3-kinase (PI3K)/mammalian target of rapamycin (mTOR) axis is responsible for aerobic glycolysis mediated by glucose transporter in epidermal growth factor receptor (EGFR)-mutated lung adenocarcinoma. J Biol Chem 290: 17495-17504, 2015.

55. Laplante M and Sabatini DM: mTOR signaling at a glance. J Cell Sci 122: 3589-3594, 2009.

56. Woo YM, Shin Y, Lee EJ, Lee S, Jeong SH, Kong HK, Park EY, Kim HK, Han J, Chang M, et al: Inhibition of aerobic glycolysis represses Akt/mTOR/HIF-1 $\alpha$ axis and restores tamoxifen sensitivity in antiestrogen-resistant breast cancer cells. PLoS One 10: e0132285, 2015.

57. Cheng SC, Quintin J, Cramer RA, Shepardson KM, Saeed S, Kumar V, Giamarellos-Bourboulis EJ, Martens JH, Rao NA, Aghajanirefah A, et al: mTOR- and HIF-1 $\alpha$-mediated aerobic glycolysis as metabolic basis for trained immunity. Science 345: 1250684,2014

58. Denko NC: Hypoxia, HIF1 and glucose metabolism in the solid tumour. Nat Rev Cancer 8: 705-713, 2008.

59. $\mathrm{Lu} \mathrm{H}$, Forbes RA and Verma A: Hypoxia-inducible factor 1 activation by aerobic glycolysis implicates the Warburg effect in carcinogenesis. J Biol Chem 277: 23111-23115, 2002.

60. Liu J, Zhang C, Hu WW and Feng ZH: Tumor suppressor p53 and its mutants in cancer metabolism. Cancer Lett 356: 197-203, 2015.

61. Vousden KH and Ryan KM: p53 and metabolism. Nat Rev Cancer 9: 691-700, 2009.

62. Yeung SJ, Pan J and Lee MH: Roles of p53, MYC and HIF-1 in regulating glycolysis-the seventh hallmark of cancer. Cell Mol Life Sci 65: 3981-3999, 2008.

63. Ogawara Y, Kishishita S, Obata T, Isazawa Y, Suzuki T, Tanaka K, Masuyama N and Gotoh Y: Akt enhances Mdm2-mediated ubiquitination and degradation of p53. J Biol Chem 277: 21843-21850, 2002.

64. Warburg O, Gawehn K and Geissler AW: Metabolism of leukocytes. Z Naturforsch B 13B: 515-516, 1958 (In German).

65. Jacobs SR, Michalek RD and Rathmell JC: IL-7 is essential for homeostatic control of T cell metabolism in vivo. J Immunol 184: 3461-3469, 2010

66. Wang R and Green DR: Metabolic checkpoints in activated T cells. Nat Immunol 13: 907-915, 2012.

67. Vander-Heiden MG, Cantley LC and Thompson CB: Understanding the Warburg effect: The metabolic requirements of cell proliferation. Science 324: 1029-1033, 2009.

68. Van der Windt GJ, Everts B, Chang CH, Curtis JD, Freitas TC, Amiel E, Pearce EJ and Pearce EL: Mitichondrial respiratory capacity is a critical regulator of $\mathrm{CD}^{+} \mathrm{T}$ cell memory development. Immunity 36: 68-78, 2012.

69. van der Windt GJ, O'Sullivan D, Everts B, Huang SC, Buck MD, Curtis JD, Chang CH, Smith AM, Ai T, Faubert B, et al: CD8 memory $T$ cells have a bioenergetic advantage that underlies their rapid recall ability. Proc Natl Acad Sci USA 110: 14336-14341, 2013. 
70. Mannava S, Grachtchouk V, Wheeler LJ, Im M, Zhuang D, Slavina EG, Mathews CK, Shewach DS and Nikiforov MA: Direct role of nucleotide metabolism in C-MYC-dependent proliferation of melanoma cells. Cell Cycle 7: 2392-2400, 2008

71. Shen Y, Wei Y, Wang Z, Jing Y, He H, Yuan J, Li R, Zhao Q, Wei L, Yang T, et al: TGF- $\beta$ regulates hepatocellular carcinoma progression by inducing Treg cell polarization. Cell Physiol Biochem 35: 1623-1632, 2015.

72. Kalathil S, Lugade AA, Miller A, Iyer R and Thanavala Y: Higher frequencies of $\mathrm{GARP}{ }^{+} \mathrm{CTLA}-4^{+} \mathrm{Foxp} 3^{+} \mathrm{T}$ regulatory cells and myeloid-derived suppressor cells in hepatocellular carcinoma patients are associated with impaired T-cell functionality. Cancer Res 73: 2435-2444, 2013.

73. Galgani M, De Rosa V, La Cava A and Matarese G: Role of metabolism in the immunobiology of regulatory $\mathrm{T}$ cells. J Immunol 197: 2567-2575, 2016.

74. Procaccini C, Carbone F, Di Silvestre D, Brambilla F De Rosa V, Galgani M, Faicchia D, Marone G, Tramontano D, Corona $\mathrm{M}$, et al: The protemic landscape of human ex vivo regulatory and conventional $\mathrm{T}$ cells reveals specific metabolic requirements. Immunity 44: 406-421, 2016.

75. Gao P, Tchernyshyov I, Chang TC, Lee YS, Kita K, Ochi T, Zeller KI, De Marzo AM, Van Eyk JE, Mendell JT, et al: c-Myc suppression of $\mathrm{miR}-23 \mathrm{a} / \mathrm{b}$ enhances mitochondrial glutaminase expression and glutamine metabolism. Nature 458: 762-765, 2009.

76. Cham CM, Driessens G, O'Keefe JP and Gajewski TF: Glucose deprivation inhibits multiple key gene expression events and effector functions in $\mathrm{CD}^{+} \mathrm{T}$ cells. J Immunol 38: 2438-2450, 2008.

77. Siska PJ, van der Windt GJ, Kishton RJ, Cohen S, Eisner W, MacIver NJ, Kater AP, Weinberg JB and Rathmell JC: Suppression of Glut 1 and glucose metabolism by decreased Akt/mTORC 1 signaling drives $\mathrm{T}$ cell impairment in B cell leukemia. J Immunol 197: 2532-2540, 2016.

78. Dang EV, Barbi J, Yang HY, Jinasena D, Yu H, Zheng Y, Bordman Z, Fu J, Kim Y, Yen HR, et al: Control of $T_{H} 17 / T_{\text {res }}$ balance by hypoxia-inducible factor 1 . Cell 146: 772-784, 2011 .

79. Chen L and Flies DB: Molecular mechanisms of T cell co-stimulation and co-inhibition. Nat Rev Immunol 3: 227-242, 2013.

80. Wieman HL, Wofford JA and Rathmell JC: Cytokine stimulation promotes glucose uptake via phosphatidylinositol-3 kinase/Akt regulation of Glut1 activity and trafficking. Mol Biol Cell 18 1437-1446, 2007.

81. Delgoffe GM, Kole TP, Zheng Y, Zarek PE, Matthews KL, Xiao B, Worley PF, Kozma SC and Powell JD: The mTOR kinase differentially regulates effector and regulatory $\mathrm{T}$ cell lineage commitment. Immunity 30: 832-844, 2009.

82. Liu C, Chapman NM, Karmaus PW, Zeng H and Chi H: mTOR and metabolic regulation of conventional and regulatory $\mathrm{T}$ cells J Leukoc Biol 7: 837-847, 2015.

83. Procaccini C, De Rosa V, Galgani M, Abanni L, Calì G, Porcellini A, Carbone F, Fontana S, Horvath TL, La Cava A, et al: An oscillatory switch in mTOR kinase activity sets regulatory T cell responsiveness. Immunity 33: 929-941, 2010.

84. Mihaylova MM and Shaw RJ: The AMPK signalling pathway coordinates cell growth, autophagy and metabolism. Nat Cell Biol 13: 1016-1023, 2011.

85. Blagih J, Coulombe F, Vincent EE, Dupuy F, Galicia-Vázquez G, Yurchenko E, Raissi TC, van der Windt GJ, Viollet B, Pearce EL, et al: The energy sensor AMPK regulates $\mathrm{T}$ cell metabolic adaptation and effector responses in vivo. Immunity 42: 41-54, 2015.

86. Dunn GP, Bruce AT, Ikeda H, Old LJ and Schreiber RD: Cancer immunoediting: From immunosurveilance to tumor escape. Na Immunol 3: 991-998, 2002.

87. Liu Y and Cao XT: Immunosuppressive cells in tumor immune escape and metastasis. J Mol Med 94: 509-522, 2016.

88. Wang TT, Liu GW and Wang RN: The intercellular metabolic interplay between tumor and immune cells. Front Immunol 5: $358,2014$.

89. Slomiany MG, Grass GD, Robertson AD, Yang XY, Maria BL, Beeson C and Toole BP: Hyaluronan, CD44, and emmprin regulate lactate efflux and membrane localization of monocarboxylate transporters in human breast carcinoma cells. Cancer Res 69: 1293-1301, 2009.

90. Hirschhaeuser F, Sattler UG and Mueller-Klieser W: Lactate: A metabolic key player in cancer. Cancer Res 71: 6921-6925, 2011.
91. Le Floch R, Chiche J, Marchiq I, Naiken T, Ilc K, Murray CM, Critchlow SE, Roux D, Simon MP and Pouysségur J: CD147 subunit of lactate/ $\mathrm{H}^{+}$symporters MCT1 and hypoxia-inducible MCT4 is critical for energetics and growth of glycolytic tumors. Proc Natl Acad Sci USA 108: 16663-16668, 2011.

92. Martinez-Outschoorn UE, Prisco M, Ertel A, Tsirigos A, Lin Z, Pavlides S, Wang C, Flomenberg N, Knudsen ES, Howell A, et al: Ketones and lactate increase cancer cell 'stemness,' driving recurrence, metastasis and poor clinical outcome in breast cancer: Achieving personalized medicine via Metabolo-Genomics. Cell Cycle 10: 1271-1286, 2011

93. Goetze K, Walenta S, Ksiazkiewicz M, Kunz-Schughart LA and Mueller-Klieser W: Lactate enhances motility of tumor cells and inhibits monocyte migration and cytokine release. Int $\mathbf{J}$ Oncol 39: 453-463, 2011.

94. Wong TY, Phillips AO, Witowski J and Topley N: Glucose-mediated induction of TGF- $\beta 1$ and MCP-1 in mesothelial cells in vitro is osmolality and polyol pathway dependent. Kidney Int 63: 1404-1416, 2003.

95. Kottmann RM, Kulkarni AA, Smolnycki KA, Lyda E, Dahanayake T, Salibi R, Honnons S, Jones C, Isern NG, Hu JZ, et al: Lactic acid is elevated in idiopathic pulmonary fibrosis and induces myofibroblast differentiation via $\mathrm{pH}$-dependent activation of transforming growth factor- $\beta$. Am J Respir Crit Care Med 186: 740-751, 2012

96. Rudrabhatla SR, Mahaffey CL and Mummert ME: Tumor microenvironment modulates hyaluronan expression: The lactate effect. J Invest Dermatol 126: 1378-1387, 2006.

97. Gottfried E, Kreutz M and Mackensen A: tumor metabolism as modulator of immune response and tumor progression. Semin Cancer Biol 22: 335-341, 2012

98. Husain Z, Huang Y, Seth P and Sukhatme VP: Tumor-derived lactate modifies antitumor immune response: Effect on myeloid-derived suppressor cells and NK cells. J Immunol 191: 1486-1495, 2013.

99. Feder-Mengus C, Ghosh S, Weber WP, Wyler S, Zajac P, Terracciano L, Oertli D, Heberer M, Martin I, Spagnoli GC, et al: Multiple mechanisms underlie defective recognition of melanoma cells cultured in three-dimensional architectures by antigen-specific cytotoxic T lymphocytes. Br J Cancer 96: 1072-1082, 2007.

100. Mendler AN, Hu B, Prinz PU, Kreutz M, Gottfried E and Noessner E: Tumor lactic acidosis suppresses CTL function by inhibition of p38 and JNK/c-Jun activation. Int J Cancer 131: 633-640, 2012

101. Gatenby RA, Gawlinski ET, Gmitro AF, Kaylor B and Gillies RJ: Acid-mediated tumor invasion: A multidisciplinary study. Cancer Res 66: 5216-5223, 2006.

102. McCarty MF and Whitaker J: Manipulating tumor acidification as a cancer treatment strategy. Altern Med Rev 15: 264-272, 2010.

103. Hu XY and Ivashkiv LB: Cross-regulation of signaling pathways by interferon-gamma: Implications for immune responses and autoimmune diseases. Immunity 31: 539-550, 2009.

104. Nathan I, Groopman JE, Quan SG, Bersch N and Golde DW: Immune (gamma) interferon produced by a human T-lymphoblast cell line. Nature 292: 842-844, 1981.

105. Mekhail K, Gunaratnam L, Bonicalzi ME and Lee S: HIF activation by $\mathrm{pH}$-dependent nucleolar sequestration of VHL. Nat Cell Biol 6: 642-647, 2004.

106. McMahon S, Charbonneau M, Grandmont S, Richard DE and Dubois CM: Transforming growth factor betal induces hypoxia-inducible factor-1 stabilization through selective inhibition of PHD2 expression. J Biol Chem 281: 24171-24181, 2006.

107. Clambey ET, McNamee EN, Westrich JA, Glover LE, CampbellEL, Jedlicka P, deZoeten EF,Cambier JC, Stenmark KR, Colgan SP, et al: Hypoxia-inducible factor-1 alpha-dependent induction of FoxP3 drives regulatory T-cell abundance and function during inflammatory hypoxia of the mucosa. Proc Natl Acad Sci USA 109: E2784-E2793, 2012.

108. Hung SP, Yang MH, Tseng KF and Lee OK: Hypoxia-induced secretion of TGF- $\beta 1$ in mesenchymal stem cell promotes breast cancer cell progression. Cell Transplant 22: 1869-1882, 2013.

109. Sanjabi S, Oh SA and Li MO: Regulation of the immune response by TGF- $\beta$ : From conception to autoimmunity and infection. Cold Spring Harb Perspect Biol 9: pii: a022236, 2017.

110. Barsoum IB, Smallwood CA, Siemens DR and Graham CH: A mechanism of hypoxia-mediated escape from adaptive immunity in cancer cells. Cancer Res 74: 665-674, 2014. 
111. Park BV, Freeman ZT, Ghasemzadeh A, Chattergoon MA, Rutebemberwa A, Steigner J, Winter ME, Huynh TV, Sebald SM, Lee SJ, et al: TGF- $\beta 1$-mediated SMAD3 enhances PD-1 expression on antigen-specific T Cells in cancer. Cancer Discov 6: $1366-1381,2016$.

112. Wei S, Shreiner AB, Takeshita N, Chen L, Zou W and Chang AE: Tumor-induced immune suppression of in vivo effector T-cell priming is mediated by the B7-H1/PD-1 axis and transforming growth factor beta. Cancer Res 68: 5432-5438, 2008.

113. Mamori S, Nagatsuma K, Matsuura T, Ohkawa K, Hano H, Fukunaga M, Matsushima M, Masui Y, Fushiya N, Onoda H, et al: Useful detection of CD147 (EMMPRIN) for pathological diagnosis of early hepatocellular carcinoma in needle biopsy samples. World J Gastroenterol 13: 2913-2917, 2007.

114. Tang J, Wu YM, Zhao P, Yang XM, Jiang JL and Chen ZN: Overexpression of $\mathrm{HAb} 18 \mathrm{G} / \mathrm{CD} 147$ promotes invasion an metastasis via alpha3betal integrin mediated FAK-paxilli and FAK-PI3K-Ca ${ }^{2+}$ pathways. Cell Mol Life Sci 65: 2933-2942, 2008.

115. Dai JY, Dou KF, Wang CH, Zhao P, Lau WB, Tao L, Wu YM, Tang J, Jiang JL and Chen ZN: The interaction of HAb18G/CD147 with integrin $\alpha 6 \beta 1$ and its implications for the invasion potential of human hepatoma cells. BMC Cancer 9: 337-346, 2009.

116. Zhao P, Zhang W, Tang J, Ma XK, Dai JY, Li Y, Jiang JL, Zhang SH and Chen ZN: Annexin II promotes invasion and migration of human hepatocellular carcinoma cells in vitro via its interaction with HAb18G/CD147. Cancer Sci 101: 387-395, 2010.

117. Baba M, Inoue M, Itoh K and Nishizawa Y: Blocking CD147 induces cell death in cancer cells through impairment of glycolytic energy metabolism. Biochem Biophys Res Commun 374: $111-116,2008$

118. Su J, Chen X and Kanekura TA: CD147-targeting siRNA inhibits the proliferation, invasiveness, and VEGF production of human malignant melanoma cells by down-regulating glycolysis. Cancer Lett 273: 140-147, 2009.

119. Huang QC, Li JB, Xing JL, Li WW, Li HW, Ke X, Zhang J, Ren TT, Shang YK, Yang HS, et al: CD147 promotes reprogramming of glucose metabolism and cell proliferation in HCC cells by inhibiting the p53-dependent signaling pathway. J Hepatol 61: 859-866, 2014

120. Ke X, Fei F, Chen YK, Xu L, Zhang Z, Huang QC, Zhang HX, Yang HS, Chen ZN and Xing JL: Hypoxia upregulates CD147 through a combined effect of HIF-1alpha and Sp1 to promote glycolysis and tumor progression in epithelial solid tumors. Carcinogenesis 33: 1598-1607, 2012.

121. Murata M, Matsuzaki K, Yoshida K, Sekimoto G, Tahashi Y, Mori S, Uemura Y, Sakaida N, Fujisawa J, Seki T, et al: Hepatitis $B$ virus $X$ protein shifts human hepatic transforming factor (TGF)-beta signaling from tumor suppression to oncogenesis in early chronic hetatitis B. Hepatology 49: 1203-1217, 2009.

122. Thiery JP, Acloque H, Huang RY and Nieto MA: Epithelial-mesenchymal transitions in development and disease. Cell 139: 871-890, 2009.

123. Xu J, Lamouille S and Derynck R: TGF-beta-induced epithelial to mesenchymal transition. Cell Res 19: 156-172, 2009.

124. Wu J, Ru NY, Zhang Y, Li Y, Wei D, Ren Z, Huang XF, Chen ZN and Bian H: HAb18G/CD147 promotes epithelial-mesenchymal transition through TGF- $\beta$ signaling and is transcriptionally regulated by Slug. Oncogene 30: 4410-4427, 2011.

125. Wang GL,Jiang BH,RueEA and Semenza GL:Hypoxia-inducible factor 1 is a basic-helix-loop-helix-PAS heterodimer regulated by cellular O2 tension. Proc Natl Acad Sci USA 92: 5510-5514, 1995.

126. Christofk HR, Vander Heiden MG, Harris MH, Ramanathan A, Gerszten RE, Wei R, Fleming MD, Schreiber SL and Cantley LC: The M2 splice isoform of pyruvate kinase is important for cancer metabolism and tumour growth. Nature 52: 230-233, 2008.

127. Kong LM, Liao CG, Chen L, Yang HS, Zhang SH, Zhang Z, Bian HJ, Xing JL and Chen ZN: Promoter hypomethylation up-regulates CD147 expression through increasing Spl binding and associates with poor prognosis in human hepatocellular carcinoma. J Cell Mol Med 15: 1415-1428, 2011.

128. Guo H, Majmudar G, Jensen TC, Biswas C, Toole BP and Gordon MK: Characterization of the gene for human EMMPRIN, a tumor cell surface inducer of matrix metalloproteinases. Gene 220: 99-108, 1998

129. Yang H, Zou W and Chen BL: Overexpression of CD147 in ovarian cancer is initiated by the hypoxic microenvironment. Cell Biol Int 37: 1139-1142, 2013.
130. Kong LM, Liao CG, Fei F, Guo X, Xing JL and Chen ZN: Transcription factor $\mathrm{Sp} 1$ regulates expression of cancer-associated molecule CD147 in human lung cancer. Cancer Sci 101: 1463-1470, 2010.

131. Kono K: Current status of cancer immunotherapy. J Stem Cells Regen Med 10: 8-13, 2014.

132. Sangro B, Gomez-Martin C, de la Mata M, Iñarrairaegui M, Garralda E, Barrera P, Riezu-Boj JI, Larrea E, Alfaro C, Sarobe P, et al: A clinical trial of CTLA-4 blockade with tremelimumab in patients with hepatocellular carcinoma and chronic hepatitis C. J Hepatol 59: 81-88, 2013.

133. Prat A, Navarro A, Paré L, Reguart N, Galván P, Pascual T, Martínez A,Nuciforo P, Comerma L,Alos L, et al: Immune-related gene expression profiling after PD-1 blockade in non-small cell lung carcinoma, head and neck squamous cell carcinoma and melanoma. Cancer Res 77: 3540-3550, 2017.

134. Cabel L, Riva F, Servois V, Livartowski A, Daniel C, Rampanou A, Lantz O, Romano E, Milder M, Buecher B, et al: Circulating tumor DNA changes for early monitoring of anti-PD1 immunotherapy: A proof-of-concept study. Ann Oncol 28: 1996-2001, 2017.

135. Patsoukis N, Bardhan K, Chatterjee P, Sari D, Liu B, Bell LN, Karoly ED, Freeman GJ, Petkova V, Seth P, et al: PD-1 alters T-cell metabolic reprogramming by inhibiting glycolysis and promoting lipolysis and fatty acid oxidation. Nat Commun 6: $6692,2015$.

136. Noman MZ, Desantis G, Janji B, Hasmim M, Karray S, Dessen P, Bronte V and Chouaib S: PD-L1 is a novel direct target of HIF-1 $\alpha$, and its blockade under hypoxia enhanced MDSC-mediated T cell activation. J Exp Med 211: 781-790, 2014.

137. Kizaka-Kondoh S, Tanaka S, Harada $\mathrm{H}$ and Hiraoka M: The HIF-1-active microenvironment: An environmental target for cancer therapy. Adv Drug Deliv Rev 61: 623-632, 2009.

138. Li B and Simon MC: Molecular pathways: Targeting MYCinduced metabolic reprogramming and oncogenic stress in cancer. Clin Cancer Res 19: 5835-5841, 2013.

139. Okkenhaug K, Graupera M and Vanhaesebroeck B: Targeting PI3K in cancer: Impact on tumor cells, their protective stroma, angiogenesis, and immunotherapy. Cancer Discov 6: 1090-1105, 2016.

140. Thorpe LM, Yuzugullu H and Zhao JJ: PI3K in cancer: Divergent roles of isoforms, modes of activation and therapeutic targeting. Nat Rev Cancer 15: 7-24, 2015.

141. Engelman JA: Targeting PI3K signalling in cancer: Opportunities, challenges and limitations. Nat Rev Cancer 9: 550-562, 2009.

142. Troncone M, Cargnelli SM, Villani LA, Isfahanian N Broadfield LA, Zychla L, Wright J, Pond G, Steinberg GR and Tsakiridis T: Targeting metabolism and AMP-activated kinase with metformin to sensitize non-small cell lung cancer (NSCLC) to cytotoxic therapy; translational biology and rationale for current clinical trials. Oncotarget 8: 57733-57754, 2017.

143. Luchsinger JA, Ma Y, Christophi CA, Florez H, Golden SH, Hazuda H, Crandall J, Venditti E, Watson K, Jeffries S, et al: Diabetes Prevention Program Research Group: Metformin, lifestyle intervention, and cognition in the diabetes prevention program outcomes study. Diabetes Care 40: 958-965, 2017.

144. Anisimov VN, Berstein LM, Egormin PA, Piskunova TS, Popovich IG, Zabezhinski MA, Kovalenko IG, Poroshina TE, Semenchenko AV, Provinciali M, et al: Effect of metformin on life span and on the development of spontaneous mammary tumors in HER-2/neu transgenic mice. Exp Gerontol 40: 685-693, 2005.

145. Dowling RJ, Zakikhani M, Fantus IG, Pollak M and Sonenberg N: Metformin inhibits mammalian target of rapamycin-dependent translation initiation in breast cancer cells. Cancer Res 67: 10804-10812, 2007.

146. Libby G, Donnelly LA, Donnan PT, Alessi DR, Morris AD and Evans JM: New users of metformin are at low risk of incident cancer: A cohort study among people with type 2 diabetes. Diabetes Care 32: 1620-1625, 2009.

147. Jiralerspong S, Palla SL, Giordano SH, Meric-Bernstam F, Liedtke C, Barnett CM, Hsu L, Hung MC, Hortobagyi GN and Gonzalez-Angulo AM: Metformin and pathologic complete responses to neoadjuvant chemotherapy in diabetic patients with breast cancer. J Clin Oncol 27: 3297-3302, 2009.

148. Christofk HR, Vander Heiden MG, Wu N, Asara JM and Cantley LC: Pyruvate kinase M2 is a phosphotyrosine-binding protein. Nature 452: 181-186, 2008. 
149. Bian H, Zheng JS, Nan G, Li R, Chen C, Hu CX, Zhang Y, Sun B, Wang XL, Cui SC, et al: Randomized trial of $\left.{ }^{131} \mathrm{I}\right]$ metuximab in treatment of hepatocellular carcinoma after percutaneous radiofrequency ablation. J Natl Cancer Inst 106: pii: dju239, 2014.

150. Calvaresi EC and Hergenrother PJ: Glucose conjugation for the specific targeting and treatment of cancer. Chem Sci 4: 2319-2333, 2013

151. Ciuleanu TE, Pavlovsky AV, Bodoky G, Garin AM, Langmuir VK, Kroll S and Tidmarsh GT: A randomised Phase III trial of glufosfamide compared with best supportive care in metastatic pancreatic adenocarcinoma previously treated with gemcitabine. Eur J Cancer 45: 1589-1596, 2009.
152. Baeuerle PA and Reinhardt C: Bispecific T-cell engaging antibodies for cancer therapy. Cancer Res 69: 4941-4944, 2009.

153. Lameris R, de Bruin RC, Schneiders FL, van Bergen en Henegouwen PM, Verheul HM, de Gruijl TD and van der Vliet HJ: Bispecific antibody platforms for cancer immunotherapy. Crit Rev Oncol Hematol 92: 153-165, 2014.

154. Smith DM, Simon JK and Baker JR Jr: Applications of nanotechnology for immunology. Nat Rev Immunol 13: 592-605, 2013.

155. Metcalfe SM and Fahmy TM: Targeted nanotherapy for induction of therapeutic immune responses. Trends Mol Med 18 72-80, 2012. 